\title{
PLC based Multilevel Automatic Car Parking System
}

\author{
Prakhar Jindal $^{1}$, Ayush Srivastava ${ }^{2}$, Harshit Paunikar ${ }^{3}$, Ritesh Kumar ${ }^{4}$, Manish Kumar ${ }^{5}$, Md. Anas $^{6}$ \\ Student, Electrical and Electronics Engineering, IMS Engineering College, Ghaziabad, India 1,2,3,4,5,6
}

\begin{abstract}
This project work presents the study and design of PLC based Multilevel Automatic Car Parking System. Multilevel car parking is the most efficient way of parking as by using this arrangement we can park most number of vehicles in least possible area. In this project we have made a prototype model of such system. The prototype model is made for accommodating nine cars at a time. Availability of space is detected by proximity sensors installed in each slot of each floor. A elevator is used to lift the car and park it at respective free slot. A PLC is used for checking vacancies and the control of the elevator. The proximity sensors installed in the system give PLC information regarding the free space as well as when the elevator has to stop depending on where the car is to be parked. This system automates the entire process of parking which reduces human error and makes best use of the available space, which inturn results in highest security. Due to these advantages, this system can be used in societies, airports, railway stations or any other place where crowding of vehicles is observed.
\end{abstract}

Keywords: PLC (Programmable Logic Controller), Proximity sensors, LLD (Ladder Logic Diagram), Prototype Model, HMI (Human Machine Interface).

\section{INTRODUCTION}

In this dynamically growing era people are facing a new has minimal chances of accident \& damage that arises in problem - lack of sufficient parking space. With families the parking area due to manual parking. The SCADA getting smaller and the total number of vehicles exceeding system monitors the whole process and gives information the total number of heads per family, the parking scenario to the operator in case any contingency occurs and takes is falling short of the current requirements in the country appropriate action itself in case some major fault occurs on by a big margin. The situation is such that on any given the basis of the programming done. This paper is divided working day approximately $40 \%$ of the roads in urban into following parts: (i)Components used (ii)Working areas are taken up for just parking the cars. The problem has been further worsened to the point where the number of families with cars has become much more than what the country is able to manage.

As it is, the cities in in the world are highly congested and on top of that the parked cars claim a lot of space that could otherwise be used in a better way. One can also add the issue of pollution to this mix and understand the enormity of the crisis. In this context it needs to be understood that most of the cities, with some possible exception, were never planned in such a way so as to accommodate a deluge of cars as is the situation now. The apathy of present day urban planners has only made the situation worse, that's where our project comes in with complete parking solution which is fully automated and compact in size.

This setup works on the most advanced industrial automation system PLC (Programmable Logic Controller) and is monitored through SCADA (Supervisory Control and Data Acquisition) system. This car parking has a circular multilevel pattern which is safe and completely driver less. The only thing person needs to do is leave the car at the ramp and then be free as the car will be automatically lifted and placed at the vacant position in the parking lot. This automated car parking also saves fuel and

\section{COMPONENTS USED}

Various components used are listed as below:

\section{A. Limit Switch}

The limit switch is a mechanical device that uses physical contact to detect the presence of an object (target). The limit switch consists of a switch body and an operating arm or plunger. The switch body includes electrical contacts to energize and de-energize a circuit. The operating head consists some type of lever arm or plunger, referred to as an actuator.

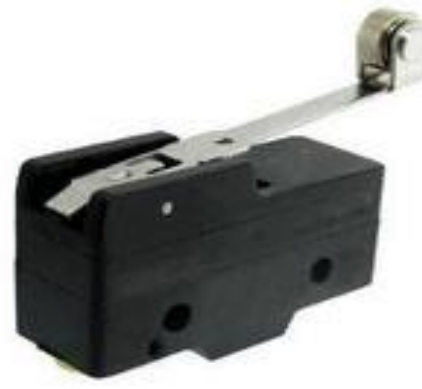




\section{International Journal of Innovative Research in Electrical, Electronics, Instrumentation and Control Engineering}

\section{ISO 3297:2007 Certified}

Vol. 5, Issue 3, March 2017

When the target comes in contact with the actuator, the actuator is rotated from its normal position to the operating position. This mechanical operation activates contacts within the switch body. Here we use the limit switch in order to control the rotation of the platform.

\section{B. Relay}

Relay are simple switches which are operated both electrically and mechanically. Relays consist of a set of contacts and also an electromagnet. The switching mechanism is carried out with the help of the electromagnet. Relays are used for controlling the various motors used in the model, when the PLC gives the signal to relay on the basis of what information it received from the sensors, relays operate and start or stop different operations

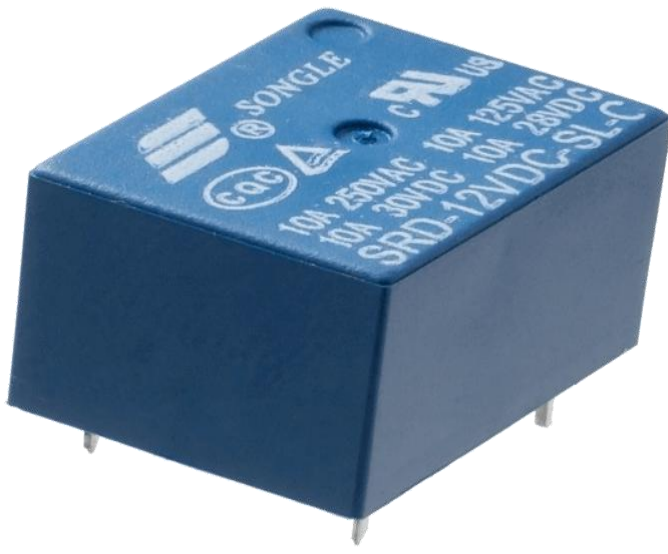

\section{D.C. Motor}

D.C. motor is the electromechanical energy converter which works from a D.C. source and generate mechanical power. In a typical D.C. motor, there are permanent magnets on the outside and a spinning armature on the inside. The permanent magnets are stationary, so they are called the stator. The armature rotates, so it is called the rotor. According to Fleming's left-hand, rule-when power supply is given the rotor rotates in the influence of magnetic field of stator magnets.

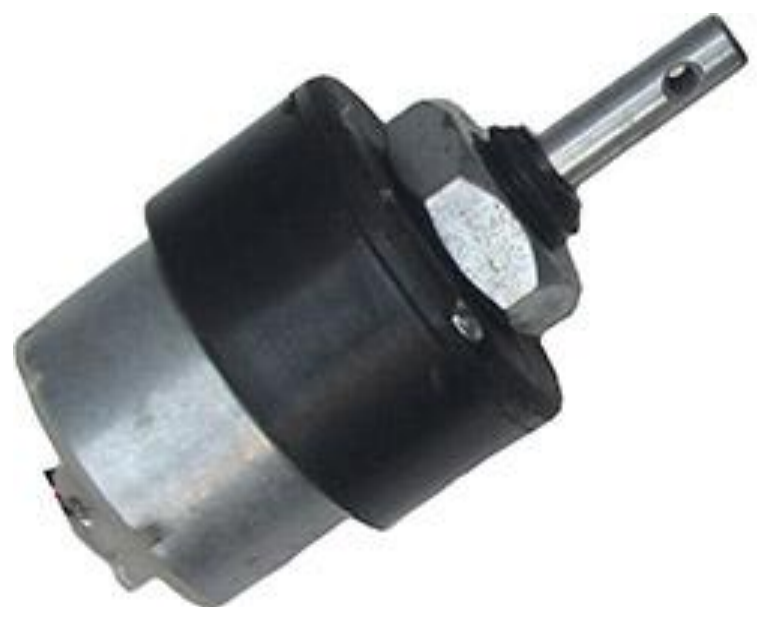

Here we use DC motor in order to perform various horizontal, vertical and rotatory motions in our project. For vertical motion we used a $20 \mathrm{rpm}$ motor and for rotatory motion we used $1.5 \mathrm{rpm}$ motor which gave higher torque as required for the application.

\section{PLC (Programmable Logic Controller)}

A Programmable Logic Controller (PLC), or programmable controller is an industrial digital computer which has been used for the control operation of machines and other equipment. This is an advanced microcontroller which is more reliable and easy to operate.

Its advanced features include:

1. Run time debugging: user can fix or change the program in the run time i.e. operation is easily controllable and accessible.

2. Remote access: with the integration of SCADA system we can see and control the things remotely. This thing will provide security assurance and quality operation

3. Speed of operation: response time of PLC program is very less hence its speed of operation is very high.

In our model we have used a DELTA PLC (DVP 14SS2) which has 8 inputs and 6 outputs.

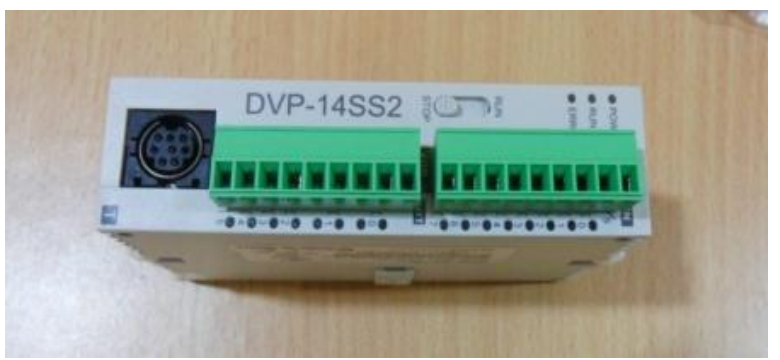

III.WORKING

As the car comes on platform we have to press a button in order to give instruction that the car has arrived for the parking. Then the rotation of the structure starts, it involves rotation of dc motor which is of $1.5 \mathrm{rpm}$. After rotating to a particular extent, it trips the limiting switch and then rotation of structure will stop.

Then dc motor which is there for lifting the ramp will start and car will start moving up, at each level of the parking area we have proximity sensors which will provide information about the level of the ramp i.e. position of car. When lift reaches to the top most sensor rotation of the lifting dc motor stop then the ramp will open up due to forward motion of dc motor with the gear assembly. Right after opening of the platform lift starts but this time in anticlockwise direction that means lift goes downwards. While moving in the downward direction it drops the car in the space so provided for the parking. This completes the parking of the car. Afterwards ramp will be closed again and lift goes down to its initial position to take another car for parking. 


\section{IV.ADVANTAGES}

Automated parking have many advantages compared to conventional parking garages like:

- Requirement of area for storing the same amount of cars is reduced to approximately half as compared to what is needed for conventional parking.

- Cars are accessible only by the owner i.e. highly secured.

- No fuel is used during the parking process as it is fully automated.

\section{SCOPE OF THE PROJECT}

The scope of this project is to design and develop a prototype of aPLC based Multilevel Automatic Car Parking System which parks and retrieves cars by an elevator. The Multilevel Automatic Car Parking System is able to maximize parking spaces at the same time minimizes parking facility construction area. All mechanisms needed to transport a car from the parking platform to the parking chambers in the autonomous multilevel car parking system are driven and controlled by Programmable Logic Controller (PLC) and the identification between cars and its owners are done by Human Machine Interface (HMI). The programming for PLC is being done via WPL soft 2.37 software using ladder logic method. Simulations of the entire system can be done in the same software for error detection and modifications purpose in prior of prototyping the entire system in real. Testing and analysing the control system will be further carried out on the developed prototype.

Parking space is not a need it's a necessity for the people. As the population increases it acquires land area for their living habitat and land area is limited so we have to use it wisely. Our project is compact in size and design and it's underground implementation will not acquire any land area as such. Hence for the future it will act as boon.

1. It has a fast operation that will save the time of people and works upon the advanced automation system that is reliable

2. Automated system is used which a future need as everything is being automated and connected over a server in order to have a secure data which is globally accessible.

3. SCADA system, which provides human machine interface is best for the part of this parking system as it, provides run time control over the system not being physically present over there.

4. This parking is driver less hence it saves fossil fuels which is limited and can't be reformed. Therefore helps in sustainable development which saves for the future generations also along with meeting needs of the present generation.
VI.CONCLUSION

The implementation of system on a large scale will definitely result in better utilization of land, less or no thefts and solves many traffic problems. The use of 'Programmable Logic Controller' makes the system reliable, easy to maintain, future proof and can be proved cost effective in long run. By increasing the number of input outputs and relays coupled together with more sensors we can create a parking for as many vehicles as required.

\section{ACKNOWLEDGMENT}

The authors would like to sincerely thank Dr. Rishi Asthanasir, HOD, Electrical and Electronics department and our mentor Snighdha Chaturvedi mam, Assistant Professor, Electrical and Electronics department, IMS Engineering College for their valuable support and help in this research.

\section{REFERENCES}

[1] http://en.wikipedia.org/wiki/Programmable_logic_controller

[2] B. L. Theraja, A. K. Theraja, "A Textbook of Electrical Technology",Sultan Chand \& Sons, 1st Multicolour Edition, Volume II, 2005, ISBN 8121-92437-5

[3] http://www.ehow.com/howdoes_5575225_pneumaticcylinderwork.html

[4] http://www.delta.com.tw/product/em/control/plc/download/manual/ SS\%20Instruction\%20Sheet-English-20060505.pdf

[5] M. A. Venkataramanan, Marc Bornstein, "A decision support system for parkingspace assignment," Mathl. Comput.Modelling Vol.15, No. 8, PP. 71-76.

[6] K. Demirli, M. Khoshnejad, "Autonomous parallel parking of Car like mobile robot by neuro-fuzzy sensor based controller" ELSEVIER Transaction on „Fuzzy sets and Systems ${ }^{\text {ee }} 160(2009)$ 2876-2891.

[7] Patrik Zips, Martin Bock, Andreas Kugi,“Optimization based path planning for car parking in narrow environments", ELSEVIER article in press ,Robotics and Autonomous systems ${ }^{\text {ee }}$

[8] Ching Hung Lee, Yu- Huiwang, Amy J.C Trappoy, "Service design for intellengent parking based on theory of inventive problem solving and service blue print", ELSEVIER Transaction on „Advanced Engineering Informatics ${ }^{e e} 29(2015)$ 295-306.

[9] Collins and Elane, Programmable Controllers-A Practical Guide, McGraw-Hill Publication 1995.

[10] Sharadchandra A. Amale, Sanjay A. Paradeshi, "A Noval Approach of Lift Control in automatic Car Parking using PLC" International Journal of Research in Engineering and Technology, eISSN:23191163/pISSN:23217308 